\title{
A imagem dos deuses: devoção e martírio na Revolução Francesa - Um ensaio sobre o romance Os deuses têm sede, de Anatole France
}

Lilian Ciarântola Walker

\section{Resumo}

Este ensaio estabelece uma relação entre religião, arte e história dentro do contexto da Revolução Francesa e por meio de uma análise do romance histórico Os deuses têm sede, de Anatole France. O texto aborda aspectos da paixão revolucionária sob um viés religioso, traçando um paralelo entre a devoção aos princípios da nova República e o culto a uma divindade. A maneira como France enxergava acontecimentos históricos, tais como a morte de Marat, as festas revolucionárias, a aprovação da Lei de Prairial, entre outros, é refletida no perfil e na vida dos personagens que são analisados neste ensaio.

Palavras-chave: Revolução Francesa - Paixão Revolucionária - Anatole France - Deuses - Religião. 
A democracia só aceita o conselho da natureza à qual incessantemente reconduz todos os homens. Seu estudo os torna bons e amantes da justiça e da equidade. É a natureza que inspira esse nobre desprendimento que eleva as almas e as torna capazes das maiores e mais bemsucedidas iniciativas. Sob seu império, todos os pensamentos, todas as ações encontram abrigo na pátria: morrer por ela é conquistar a imortalidade... ${ }^{1}$ Jacques Louis-David (I748-I825) ${ }^{2}$

A mesma paixão com que fala David está presente em Evariste Gamelin, personagem central do romance de Anatole France e pupilo do pintor revolucionário dentro da história. Em ambos, há uma confluência entre a vocação artística e a vocação patriótica, núcleo no qual France tece uma reflexão a respeito da postura moral da personagem diante dos episódios do Terror. É no campo da sensibilidade e da devoção de Gamelin aos seus ideais, espelhados na trajetória de David, que o autor revela a potência da fé revolucionária e do culto aos seus deuses.

Assim como David, que não somente expressava sua simpatia pela causa da Revolução, mas atuava ativamente em favor dela, Gamelin se torna, em determinado momento da história, um jurado do Tribunal Revolucionário. A partir desse momento, tendo poder para condenar ou absolver os inimigos da pátria, seus valores e ideais são colocados à prova e em conflito com a natureza doce e sensível do artista.

Já nas primeiras páginas, France nos descreve Evariste como um pintor comprometido com os princípios do neoclassicismo heroico, que reconhece na arte do passado "a depravação monárquica e o efeito vergonhoso da corrupção das Cortes" (FRANGE, I979, p. I5). Entusiasta da nova estética, urgia por pintar as virtudes republicanas e as liberdades, mas tinha de se dedicar a obras medíocres e composições alegóricas a fim de contentar o gosto do vulgar.

A primeira tela de Gamelin descrita no romance nos oferece um paralelo interessante com uma pintura de David, datada do ano da Revolução. Permanecendo inacabada até o final da história, a obra de Gamelin retrata um Orestes

I DAVID, J. L. apud SABORIT, I989, p. I7I.

2 Jacques Louis-David (I748-I825) foi um pintor francês, um marco do neoclassicismo, movimento que rompia com o rococó. Apoiou a Revolução Francesa desde o início, era amigo de Robespierre e membro do Clube dos Jacobinos. Enquanto outros artistas deixavam o país para estudar em outras academias (a maioria em Roma), David permaneceu para auxiliar na queda do Antigo Regime; votou pela morte do rei, fechou a Academia francesa a mando da Convenção, atuou como propagandista da Revolução, trabalhou na encenação de diversas festas cívicas, concebendo a cenografia dos cultos à Razão e ao Ser Supremo, e organizou também as cerimônias do Panteão, templo dedicado a homenagear os homens ilustres da Revolução. David foi preso depois da queda de Robespierre e, ao sair, tornou-se o pintor oficial de Napoleão (JoHnSON, 2006). 
e sua irmã Electra ${ }^{3}$, que afasta os cabelos negros da fronte do irmão debilitado. France destaca que nela havia gênio e naturalidade e acrescenta que o rosto de Orestes se assemelhava ao de Gamelin. A identificação do pintor com o personagem mitológico não é um detalhe irrelevante, uma vez que France retoma a menção a essa tela e a semelhança entre os dois personagens por algumas vezes durante o romance. Numa dessas vezes, Gamelin tem uma espécie de delírio e sente como se estivesse vivendo a cena de Orestes, enquanto tenta se convencer: "[...] não sou parricida. Pelo contrário, foi por piedade filial que verti o sangue impuro dos inimigos da pátria" (FRANCE, I979, p. 254). Tal como a narrativa mitológica, que trata do sacrifício da família como punição pela traição, no quadro de David, Os lictores levando a Brutus os corpos de seus filhos, de I789, o cônsul ordena a execução de seus filhos por haverem conspirado contra a República romana. A defesa heroica pelo amor patriota, que exige o sacrifício do insacrificável, assemelha-se ao furor do filho que vinga a traição contra o pai por meio do matricídio. A deusa Roma, na pintura de David, figura entre o pai e o cadáver do filho, revelando que o amor por ela antecede o amor pela família.

Transportando-nos para a França, no cenário da Revolução, Ignasi Saborit nos lembra que "o patíbulo erguido pela França para sua regeneração destina-se aos franceses. Em última instância, o próprio patriotismo enobrece o sangue do filho justiçado" (SABORIT, I989, p. I83). É este chamado à devoção à Pátria, "a única que enaltece aquele que morre por seu amor" (SABORIT, I989, p. I83) e que consome e sobrepuja os demais amores, que France imprime em seu personagem, como nos revela o episódio em que Evariste resiste, implacável, ao pedido da irmã pela absolvição de seu marido. Na cena do julgamento, a pintura de David é evocada por uma escultura de Brutus que se encontra no tribunal. Gamelin, após ver o cunhado, fixa os olhos no busto e declara:

Gidadão presidente, embora possa existir entre um dos acusados e eu laços que, se fossem declarados, seriam laços de aliança, declaro nada me recusar. Os dois Brutus não se recusaram quando, para salvação da República ou da causa da liberdade, lhes foi preciso condenar um filho, matar um pai adotivo (FRANCE, I979, p. 250).

$3 \mathrm{Na}$ mitologia grega, Orestes e Electra são filhos de Agamemnon e Clitemnestra. Clitemnestra trai o marido com Egisto e Apolo ordena que Orestes vingue o pai assassinando sua mãe e o amante. Ao cumprir o que querem os deuses, Orestes ascende ao poder, mas um mal passa a consumi-lo e ele fica de cama. Segundo Electra, é o sangue da mãe que provoca a doença (MALHADAS, 2003). 
A metamorfose de Gamelin ao longo do romance é clara. France engendra o desdobramento das paixões ideológicas do personagem, que se intensificam especialmente a partir de sua atuação no Tribunal Revolucionário. Mas, já no início da história, o autor nos dá indícios de sua crítica, apontando a Revolução como causa de um processo de desumanização em Gamelin. No momento em que Elodie Blaise, a filha do comerciante de estampas, por quem Evariste se apaixona, começa a divagar sobre ele e a possibilidade de se unirem, France denuncia: "O que a tranquilizava [...] era saber com toda a certeza [...] que Evariste, antes que a Revolução tivesse feito dele um herói, tinha amado muito humanamente uma mulher, uma humilde criatura, a porteira da academia" (FRANCE, I979, p. 32-33). No decorrer dos acontecimentos, a fixação pela Revolução começa a cegar Gamelin, fazendo com que ele visse "por toda a parte conspiradores e traidores" (FRANCE, I979, p. I73).

A desconfiança cega e constante em torno da ameaça de traição era, de fato, um assunto sensível para Anatole France. Poucos anos antes de publicar Os deuses têm sede (IgI2), ele havia participado da defesa de Alfred Dreyfus, um oficial do exército francês, acusado injustamente de trair a França por prestar serviços de espionagem aos prussianos. Mesmo após o surgimento de evidências a favor da inocência de Dreyfus, a sentença foi mantida, e o caso se estendeu por aproximadamente doze anos, até a liberdade do capitão em I906. ${ }^{4}$ $\mathrm{Na}$ época, France denunciava a cegueira do Estado e criticava a confiança dos franceses nesta instituição e no clero. Não é de se admirar, portanto, que no romance ele acuse a arbitrariedade dos julgamentos revolucionários, com especial acidez a partir da promulgação da lei de 22 de Prairial ${ }^{5}$ no ano II: "Nem instruções, nem interrogatórios, nem testemunhas, nem defensores: o amor da Pátria suplanta tudo” (FRANCE, I979, p. 248).

\footnotetext{
4 Dreyfus, de origem judaica, foi condenado por alta traição em I894 e a farsa das acusações foi acobertada por uma onda de nacionalismo e antissemitismo que crescia na Europa no final do século XIX. O caso dividiu a França entre os dreyfusards e os antidreyfusards, e essa divisão, de certa forma, marcava o debate entre uma direita que apoiava o retorno à monarquia juntamente com a hierarquia católica e uma ala da esquerda apoiando a República. Em I906, o processo foi revisado e comprovou-se a culpa de Charles-Ferdinand Walsin Esterhazy, outro major do exército francês (DENIS, 2002).

5 A lei de Prairial simplificava o processo judicial, suprimindo o interrogatório do acusado antes da audiência no tribunal, recusando ao acusado a ajuda de um defensor e limitando a sentença do juiz à absolvição ou à pena capital. O artigo 8 desta lei estatuía que "a regra dos julgamentos é a consciência dos jurados esclarecida pelo amor da pátria; a sua finalidade, o triunfo da República e a ruína dos seus inimigos; o processo, os meios simples que o bom senso indicar para que se chegue ao conhecimento da verdade nas formas que a lei determinar" (STEWART, I95I, p. 528-53I.).
} 
Apesar das severas denúncias e do tom irônico utilizado por France em Os deuses têm sede, o livro não pode ser considerado contrarrevolucionário ou de direita. France não compactua com um conservadorismo reacionário, mas mantém seus ideais de republicano socializante, até defender o comunismo no final da vida ${ }^{6}$. Assim, ele não condena Gamelin por seus princípios e seu idealismo. Ao mesmo tempo em que satiriza e ataca amargamente a violência dos homens no governo revolucionário, ele ainda consegue compreendê-los e simpatizar com sua ingenuidade. Segundo Marcelo Coelho, autor do prefácio da edição de 2007 :

[...] ao denunciar a desumanidade dos revolucionários, a literatura de France invoca menos a presença de homens concretos, contraditórios, doentes ou fanáticos e mais o seu próprio ideal de Humanidade - uma humanidade fraca, falível, mas afinal de contas fácil de entender e perdoar (GOELHO apud FRANCE, 2007, p. I2).

Escrevendo na iminência da Primeira Guerra Mundial, numa época que sentia os sintomas da confiança extrema no positivismo, na modernização e na ciência, France estabelece como alvo de suas críticas a devoção religiosa ao homem e à razão. Em seu outro romance, $O$ crime de Sylvestre Bonnard, membro do Instituto (I88I), a história já testemunha o ceticismo de France, que se veste com a figura do personagem principal ${ }^{7}$, um historiador erudito-intelectual que perde a fé no próprio ofício por desconfiar do progresso e se desencantar pela ciência e pelos estudos, tomando-os como estéreis. No caso da obra aqui analisada, não é em nosso pintor, mas no cidadão Maurice Brotteaux des Ilettes que o autor se encontra (COELHO apud FRANGE, 2007, p. I4); é por meio da voz do ex-aristocrata, provocador anticlerical, que France irá falar sobre sua resistência à concepção divina da razão:

\footnotetext{
6 Apesar de ser muito criticado por sua moderação (especialmente pelos comunistas e surrealistas), France apoiou movimentos de esquerda, defendeu a República e criticou fortemente o nacionalismo e o antissemitismo dos conservadores. A experiência com o caso Dreyfus o aproximou ainda mais da esquerda socialista e da crítica social, levando-o a escrever livros como Opiniões sociais (I902) e Rumo aos novos tempos (I906), que apresentam um tom mais otimista sobre a humanidade e trazem iluminações sobre o socialismo (MARIÁTEGUI, 2005).

7 Para Marie-Claire Bancquart, especialista nas obras de Anatole France, uma das chaves de interpretação é a associação entre personagem e romancista, entre o percurso da criatura e o de seu criador. Esta associação se dá em função do caráter dissertativo, psicológico, de tese e ideias presentes em muitas das obras de France (ALMEIDA, 20I3). Sobre $O$ crime de Sylvestre Bonnard, membro do Instituto, ver HAIDUKE (2OII, p. I75-I85).
} 
[Gamelin]:

- [...] Espero, pelo menos, cidadão Brotteaux, que quando a República tiver instituído o culto da Razão, não recuse a sua adesão a uma religião tão sábia.

- Tenho o amor pela Razão, e não tenho por ela o fanatismo - respondeu Brotteaux. - A Razão conduz-nos e ilumina-nos; quando fizer dela uma divindade, ela o cegará e o persuadirá a cometer crimes (FRANGE, I979, p. 75).

Para o sábio Brotteaux, ateu e leitor de Lucrécio, era deplorável que os jacobinos quisessem instituir uma nova religião no lugar do catolicismo; a religião da Razão, da Liberdade e da Pátria, por ser mais jovem, era, segundo ele, mais maligna e cruel. France, que empresta o seu materialismo cético e epicurista a Brotteaux, acredita na busca do prazer como fim único da vida e, contrapondo-se à visão otimista de Gamelin a respeito da virtude natural do homem, concebe o egoísmo e a avareza como os verdadeiros atributos naturais, sendo a moral um expediente imaginário para que os homens convivam melhor uns com os outros (FRANCE, I979). Através dessa lente, France nos mostra, em seu romance, não somente por meio de Brotteaux, suas perspectivas sobre a escalada da razão rumo ao caráter divino, fato relacionado ao fenômeno de descristianização ${ }^{8}$ que vinha sendo impulsionado durante a Revolução Francesa.

Michel Vovelle destaca duas dimensões da campanha conquistadora da Razão: uma destrutiva, fazendo tábua rasa das religiões estabelecidas, e uma reconstrutiva, compensando a destruição pela tentativa de criar um novo culto cívico, o culto da Razão. Na primeira, constam o encerramento das igrejas, a destruição dos objetos sagrados, o confisco das pratas e sinos, a abdicação e expulsão dos sacerdotes, o casamento dos padres, a mudança do calendário e a obrigação dos clérigos de assinar o juramento à Constituição ${ }^{9}$. Vários desses fatores são referidos de alguma forma no romance ${ }^{\mathrm{IO}}$, mas a figura que

8 É importante compreender este conceito à luz dos termos "desclericalização" e "secularização", e não como a perda do sentimento religioso. Como nos esclarece Ozouf, "o sentimento revigorou-se durante a Revolução" (OZOUF, I989, p. 38). O que a Revolução comunica, na verdade, é uma incompatibilidade entre os novos princípios e a antiga religião, ainda muito identificada com o Antigo Regime. Pretende, portanto, substituir os símbolos associados a ele, instituindo novas formas de culto que se relacionassem mais intimamente aos valores da República.

9 Outras expressões foram a substituição da cruz pelas árvores da Liberdade, as mascaradas antirreligiosas e os autos-de-fé, mas esses já revelam o início da atividade de reconstrução (VOVELLE, 2007, I989).

Io Ver FRANCE, I979, p. 5 (descrição da substituição de uma antiga igreja pela assembleia da Seção da Ponte Nova: destruição dos emblemas religiosos, santos martelados e substituídos pelos heróis da República, altar despojado e sob a Declaração dos Direitos); p. 8 (Gamelin oferece a Trubert a lista dos sinos que serão enviados para o Luxemburgo para serem transformados em canhões); p. I56-I58 
melhor exemplifica esse aspecto da descristianização é o personagem Louis de Longuemare, um clérigo da ordem dos Barnabitas que teve de abandonar seu convento por este ter sido transformado em sede da Seção da Ponte Nova. Após ser expulso, a Assembleia passa a lhe conceder uma magra pensão até o momento que exige o seu certificado de civismo. Quando o padre requer o certificado na Câmara Municipal, o oficial lhe diz que só poderia oferecê-lo aos que haviam provado o seu civismo em três datas diferentes e, não podendo satisfazer tal exigência, Longuemare tem de se refugiar na casa de Brotteaux para não ser preso pelo Comitê de Segurança Geral. O padre conta a Brotteaux que havia se dedicado a compor uma obra de extensão sobre a perseguição da Igreja na França e para demonstrar que o juramento constitucional dos padres era contrário à disciplina eclesiástica. Outra referência interessante é o episódio da prisão de Longuemare e de Brotteaux, no qual France descreve os demais prisioneiros: "Os prisioneiros que a sorte tinha reunido naquela cela eram monárquicos ou federalistas; até lá havia um jacobino; diferiam nas opiniões sobre a maneira de conduzir os assuntos do Estado, mas nenhum guardava a menor réstea de crenças cristãs" (FRANGE, I979, p. 23I). (Grifos meus)

A intenção que se expressa nessa etapa destruidora é a de abolir a lembrança do passado monarquista, ao qual se associavam o fanatismo e a superstição. O que se segue é uma reforma da toponímia como medida reconstrutora, a fim de opor, às antigas doutrinas, um deísmo patriótico e uma moral republicana. Dessa dimensão fizeram parte os banquetes e quaresmas cívicas, as festas em honra da deusa Razão, as festas cívicas em honra das vitórias, as festas decadárias, o culto aos mártires da Liberdade e os cultos ao Ser Supremo (VOVELLE, I989). No livro, France cita o culto ao mártir Marat e menciona diversas vezes o culto à Razão e ao Ser Supremo. Além disso, ele atribui ao posicionamento de Gamelin uma espécie de devoção religiosa: "Aos propósitos indiferentes de Jean Blaise [Gamelin] opunha sua fé revolucionária” (FRANCE, I979, p. 40).

[...] [Gamelin] concebia uma metafísica revolucionária, que elevava o seu espírito acima das grosseiras contingências, ao abrigo dos erros dos sentidos, na região das certezas absolutas. [...] Gamelin experimentou a alegria profunda do crente que sabe a palavra que salva e a palavra que perde. Doravante, o Tribunal Revolucionário, como outrora os tribunais eclesiásticos, conheceria o crime

\footnotetext{
(Longuemare narra sobre a exigência do juramento constitucional e o casamento dos padres); p. I99-200 (o sapateiro usa o novo calendário diante da mãe de Gamelin); p. 2II (uma senhora é levada ao Comitê de Vigilância por vender artigos religiosos).
} 
absoluto, o crime verbal. E, porque tinha espírito religioso, Evariste recebia estas revelações com um entusiasmo sombrio; o seu coração exultava-se e rejubilava com a ideia que daí em diante, para distinguir o crime da inocência, possuía um símbolo. Ó tesouros da fé! Arranjam lugar para tudo! (FRANGE, I979, p. I67).

A conduta devota de Gamelin diante das doutrinas e crenças da nova República exprime a essência do projeto de proclamação da Razão. Os novos princípios exigiam uma nova postura, em muitos casos, produzida pelo apelo de uma retórica persuasiva. Em algumas passagens do romance, ficam nítidos o entusiasmo e a fé com que Gamelin e outros jacobinos recebiam os discursos de Robespierre (FRANGE, I979, p. I65-I69, 237-240, 276). De fato, surgia toda uma pedagogia, empenhada em disseminar os valores revolucionários e que tratava de substituir a tradição do passado por um novo imaginário, uma nova moral, uma nova estética. Nesse sentido, a arte desempenhou um papel fundamental:

A Revolução, que em suas origens era plenamente filosófica e plenamente política, suscitou tantos sentimentos novos que lhe foi preciso também tornar-se religiosa, no sentido de encontrar para a arte um ideal e um foco de inspiração. As concepções mais elevadas do espírito humano, as virtudes morais e cívicas e os dons da Natureza foram tomados em seus sentidos figurados e em suas formas alegóricas, substituindo as personalidades, os ídolos e as superstições do passado (RENOUVIER apud SABORIT, I989, p. I78).

A escultura feita por Joseph Chinard, um escultor francês que vivia temporariamente em Roma, é emblemática: denominada A Razão subjugando o fanatismo (I792), nela vemos a Razão representada por um Apolo alado, envolto por raios de sol e de pé sobre uma mulher agachada que veste um hábito de freira (CROW, I995). De forma semelhante, as panteonizações, efígies e cortejos em honra dos mártires da Revolução constituem um significativo corolário do esforço de renovação do imaginário nacional.

Comparável ao processo de endeusamento da Razão foi frequente uma associação dos heróis que lutaram e morreram em prol da pátria à figura de deuses. Vovelle chega a mencionar uma "trindade revolucionária", representada por Marat, Chalier e Lepeletier (VOVELLE, I989, p. I33) ${ }^{\text {II }}$. Sem dúvida,

II Os cultos a essas figuras não são um fenômeno homogêneo. Encontramos variações nas diferentes regiões da França, em que há predominância de um herói em relação aos outros, ou mesmo a inexistência do culto onde as modificações da toponímia foram muito medíocres (VOVELLE, I989, p. I34). 
Marat é o que se destaca, é transfigurado em mártir fundador e, com ele, “a luta pela era da razão atinge assim seu ponto supremo, quando exige e celebra o holocausto do lutador" (COLI, 20IO, p. 25-26). Litanias são escritas em sua homenagem ${ }^{12}$ e um ex-padre em Arles chega a declarar: "Não devemos ter outra divindade senão Marat" (VOVELLE, I989, p. I35). David, encarregado de produzir várias das obras que buscaram eternizar a figura dos mártires, emprega especial dedicação no quadro A morte de Marat (I793), evocando a figura de Cristo da pintura de Caravaggio, O sepultamento de Cristo (I603-4) (ARGAN, I992). A pose de Marat, o instrumento de violência, as inscrições, a tábua de madeira, a composição perpendicular são todos elementos que se inspiram na representação do sacrifício de Cristo (CROW, I995). Gamelin expressa o mesmo tipo de devoção pelo Amigo do Povo, a quem "venerava, idolatrava" (FRANCE, I979, p. 54). Mesmo antes de ser assassinado, Marat é visto pelo personagem como um salvador: "Confiemos em Marat. Este ama o povo, conhece os seus verdadeiros interesses e serve-os. Foi sempre o primeiro a desmascarar os traidores, a deslindar as conjuras. É incorruptível e sem medo. Só ele é capaz de salvar a República em perigo" (FRANCE, I979, p. 20).

France também retrata um cortejo em homenagem a Marat que, de cima de um carro, diz aos concidadãos: "Sejam tal como eu, patriotas até à morte" (FRANCE, I979, p. 53-54). Depois da morte, relatada no romance, ele continua sendo citado e representado como um modelo para Gamelin. ${ }^{\mathrm{I} 3}$ A morte deixa de ser um fim em si mesmo quando a vida é dedicada à pátria. Assim como o sangue do filho justiçado é enobrecido pelo amor à pátria, o do filho injustiçado igualmente o é. A heroificação se torna o âmago da nova sensibilidade coletiva, e a morte é enfrentada com conformidade, por se entender a vida menos importante do que a salvação da pátria.

À medida que a história caminha para o seu final, Gamelin, percebendo a desilusão e o desprezo gradativos do povo pela Revolução, afirma que é preciso salvar a pátria apesar dela mesma e, "quando pedisse clemência, tapar os ouvidos e matar" (FRANCE, I979, p. 267). Aqui, o personagem se apodera da figura de herói e alega o sacrifício da própria vida pela pátria; proclama: "A Pátria maldizia os salvadores. Que nos maldiga, mas que seja salva!" (FRANCE, I979, p. 267). Ao se deparar com uma criança, segue dizendo: "Pequeno, tu

12 "Ó coração de Jesus, ó coração de Marat" (VOVELLE, 2007, p. 213).

I3 Ver FRANCE, I979, p. 92-94 (assassinato de Marat); p. 97 (Gamelin compra um anel com o relevo da cabeça de Marat para Elodie); p. IO8 (busto de Marat é colocado junto do de Le Peltier e Gamelin toma como testemunho "as mãos augustas de Marat, mártir da liberdade"). 
crescerás livre, feliz, e devê-lo-ás ao infame Gamelin. Sou atroz para que sejas feliz. Sou cruel para que sejas bom, sou impiedoso para que amanhã todos os franceses se abracem vertendo lágrimas de alegria” (FRANCE, I979, p. 269). É neste momento que Evariste reconhece a morte iminente, crendo, como Robespierre, que "uma 'morte prematura' é o preço que tem a pagar o 'homem virtuoso'” (ROBESPIERRE apud GUENIFFEY, I989, p. 3I2). Após ver o herói Robespierre tombado, numa tentativa de concretizar com as próprias mãos o seu martírio, Gamelin dirige a lâmina de um canivete contra o seu coração, mas acaba ferindo apenas os dedos e uma costela. O sacrifício mal sucedido é compensado pelo castigo supremo, por meio do qual se igualaria a Robespierre:

Vou morrer - pensou ele. - É justo que recebamos estes ultrajes lançados à República e de que a deveríamos defender. Fomos fracos; somos culpados de indulgência. Traímos a República. Merecemos a nossa sorte. O próprio Robespierre, o puro, o santo, pecou por doçura, por mansidão; as suas faltas foram apagadas pelo seu martírio. Como ele, traí a República; ela morre: é justo que eu morra com ela. Poupei o sangue: que o meu sangue corra! Que eu morra! Mereço... (FRANGE, I979, p. 286).

A caminho do cadafalso, as mulheres que antes insultavam os aristocratas e indulgentes enviados para a guilhotina por Gamelin agora proferiam contra ele: "Vá, bebedor de sangue!" (FRANCE, I979, p. 285). Passado o Terror, a acusação é também aplicada nas estampas da moda, nas quais Robespierre é retratado como tirano que aperta um coração para beber o sangue (FRANCE, I979, p. 289). Desse modo, France ilustra o título do romance, retirado da frase do imperador Montezuma, que justificava o hábito asteca de sacrificar os seres humanos afirmando que os deuses tinham sede de sangue (COELHO apud FRANCE, 2007, p. I4).

Tal é a visão de France a respeito dos deuses erguidos durante a Revolução Francesa. Cada ídolo ao qual se atribuía divindade exigia de seus fiéis os mais terríveis crimes e sacrifícios. A Pátria, "divindade nova para um povo livre" (SABORIT, I989, p. I53), reivindicava o sangue dos filhos traidores; a Razão, filha da Natureza e mãe da Verdade (VOVELLE, I989), deusa que regenerava o espírito humano, escondia os monstros mais secretos e hediondos desse ser racional, cegando-o e persuadindo-o a cometer loucuras; o Ser Supremo, fonte de todas as virtudes (FRANCE, I979, p. 75), princípio da moral republicana, ao confiar na natureza, expunha os homens à sua própria crueldade; e os mártires, heróis da República, inspiravam seus devotos a se sentirem tão fortes e poderosos quanto eles, fazendo de sua entrega sacrificial o modelo a ser seguido. 
Por meio do ateísmo de Brotteaux, France elabora um antiteísmo que aplica o conflito epicurista ${ }^{\mathrm{I} 4}$ com o Deus cristão a todas as figuras que o substituem. Por enxergar fracasso nas investidas religiosas da Revolução, atribuindo-lhes a causa de uma violência igual ou pior que a da fé cristã, a premissa de que Deus é mau ou impotente se torna válida para os deuses revolucionários. O final do livro coroa essa alegação ao retratar o desgosto do povo em relação aos ídolos. As estampas que desvirtuavam Robespierre, as zombarias proferidas contra os jacobinos e as destruições dos bustos de Marat demonstram a frustração dos franceses. Seus deuses os haviam traído: não conseguiram conter os problemas e se mostraram tão malignos quanto os demais.

Numa discussão com Gamelin, Brotteaux afirma: "A humanidade copia os seus deuses dos seus tiranos, e o senhor, que rejeita o original, guarda a cópia!" (FRANCE, I979, p. 75). Para ele, a raça humana não poderia desejar um culto a deuses justos e benevolentes, dos quais não teriam nada a temer (FRANCE, 1979). Em última instância, a maldade está no próprio homem, pois é ele quem constrói a imagem dos seus deuses. France chega a conceder uma espécie de sedução ao mal, quando mostra a progressiva atração de Elodie por Gamelin: "quanto mais ele lhe parecia terrível, cruel, atroz, quanto mais o via coberto do sangue das suas vítimas, mais tinha fome e sede dele" (FRANCE, I979, p. 206).

Nesse sentido, a moral de France se assemelha à de Sade, que crê ser melhor depender de uma natureza cega do que de um ser cujas boas qualidades, só afirmadas pelos teólogos, são constantemente desmentidas pelos fatos (SABORIT, I989). Ele contraria Rousseau e defende que "a moral não é mais que um esforço desesperado dos nossos semelhantes contra a ordem universal, que é a luta, o jogo cego das forças contrárias" (FRANCE, I979, p. 76); acredita que devemos amar e buscar a virtude, mas tendo a consciência de que ela é contrária à nossa natureza.

$\mathrm{O}$ autor assinala a contraditoriedade e a ingenuidade dos jacobinos por entender que se deve governar os homens tais como são, e não como gostaria que fossem (FRANCE, I979, p. I26). O bem e a generosidade parecem provir, para France, do próprio egoísmo humano que faz com que nos identifiquemos na fraqueza do outro. Após acolher o padre Longuemare em sua casa, Brotteaux assegura:

I4 A lógica do paradoxo proposto por Epicuro é citada por Brotteaux no romance: "Epicuro disse: 'Ou Deus quer impedir o mal e não pode, ou pode e não quer. Se quer e não pode, é impotente; se pode e não quer, é perverso; se não pode nem quer, é impotente e perverso; se pode e quer, por que não o faz, meu pai?'” (FRANCE, I979, p. I8I). 
[...] não o faço por amor ao senhor. [...] Faço-o por aquele egoísmo que inspira ao homem todos os atos de generosidade e dedicação, fazendo-o reconhecer-se em todos os miseráveis, dispondo-o a lamentar o seu próprio infortúnio no infortúnio alheio e levando-o a auxiliar mortal semelhante a ele pela natureza e pelo destino, até acreditar que se socorre a si mesmo socorrendo-o (FRANCE, I979, p. I58-I59).

Contudo, creio que essa visão negativa da natureza humana apresentada no romance não pretende responder ao dilema sobre a origem do mal, isto é, se está no homem ou no sistema. Talvez, no final, não se trate de resolver a questão, mas levar-nos a discuti-la juntos, como Brecht faria alguns anos depois, no epílogo de uma de suas peças, em que pede a opinião do público:

Se fossem outros os homens, ou se outro fosse o mundo,

Ou se os Deuses fossem outros ou nenhum - como seria?

[...] Na vossa opinião, que devemos fazer?

Mudar o mundo ou a natureza humana?

Acreditar em causas maiores e melhores - ou em nada?

Teremos que encontrar cada um sozinho

Ou procurarmos juntos?

(BRECHT, I959, p. I84).

Ao caracterizar uma humanidade simultaneamente fraca e compreensível, o interesse de France está, acima de tudo, em tentar entendê-la e fazer-nos reconhecer nela. Ele se identifica na limitação do homem em compreender a si mesmo, crendo que nossa própria constituição nos obriga a criar quimeras e explicações que tragam sentido à nossa existência. Porém, apesar de seu ceticismo, parece reconhecer a importância de buscarmos esse conhecimento como meio de nos aperfeiçoar e alcançar caminhos mais justos.

\section{Referências bibliográficas}

ALMEIDA, Milene Suzano. Humanismo satírico em Lima Barreto e Anatole France. Tese de doutorado, Faculdade de Filosofia, Letras e Giências Humanas, São Paulo, 20I3, $256 f$.

ARGAN, Giulio Carlo. Arte moderna: do iluminismo aos movimentos contemporâneos. São Paulo: Companhia das Letras, I992.

BRECHT, Bertolt. A alma boa de Setsuan. Rio de Janeiro: H. Antunes, I959 [I938-40]. 
COLI, Jorge. O corpo da liberdade: reflexões sobre a pintura do século XIX. São Paulo: Cosac Naify, 20Io.

CROW, Thomas. Emulation: making artists for revolutionary France. Londres: Yale University Press, I995.

DENIS, Bernoît. Literatura e engajamento: de Pascal a Sartre. São Paulo: Edusc, 2002, p. 209-234.

FRANGE, Anatole. Os deuses têm sede. Tradução. São Paulo: Otto Pierre, I979. (Os grandes romances históricos, vol. 37)

. Os deuses têm sede. Tradução. São Paulo: Boitempo, 2007, p. I2-I4.

FURET, François \& Ozouf, Mona (org.). Dicionário crítico da Revolução Francesa. Tradução. Rio de Janeiro: Nova Fronteira, I989.

HAIDUKE, P. R. A. O crime de Sylvestre Bonnard, membro do Instituto, de Anatole France: uma dramatização dos dilemas da erudição histórica. Revista de Literatura, História e Memória. Cascavel, vol. 7, nº IO, 20II, p. I75-I85. (http://e-revista. unioeste.br/index.php/rlhm/article/view/5662).

HUNT, Lynn Avery. Política, cultura e classe na Revolução Francesa. São Paulo: Companhia das Letras, 2007.

JOHNSON, Dorothy. Jacques-Louis David: New perspectives. Newark: University of Delaware Press, 2006, p. 70-80; 107-130.

MALHADAS, Daisi. Tragédia grega: o mito em cena. Cotia, SP: Ateliê, 2003, p. 5I-74.

MARIÁTEGUI, J. C. Do sonho às coisas: retratos subversivos. São Paulo: Boitempo, 2005 , p. 75-79.

SABORIT, Ignasi. Religiosidade na Revolução Francesa. Tradução. Rio de Janeiro: Imago: ISER, I989.

STEWART, John Hall. A documentary history of the French Revolution. Nova York: Macmillan, I95I, p. 528-53I.

VOVELLE, Michel. A Revolução Francesa: I789-I799. Lisboa: Edições 70, 2007. A Revolução Francesa contra a Igreja: da Razão ao Ser Supremo. Rio de Janeiro: Jorge Zahar, I989. 